\title{
REPETIBILIDADE DE CARACTERÍSTICAS FORRAGEIRAS DO CAPIM-ELEFANTE'
}

\author{
Aldo Shimoya ${ }^{2 *}$; Antônio Vander Pereira ${ }^{3}$; Reinaldo de Paula Ferreira ${ }^{3}$; Cosme Damião Cruz \\ Pedro Crescêncio Souza Carneiro ${ }^{4}$ \\ ${ }_{3}^{2}$ PESAGRO-RIO - Estação Experimental de Campos, C.P. 114331 - CEP: 28080-000 - Campos dos Goytacazes, RJ. \\ ${ }^{3}$ Embrapa Gado de Leite, R. Eugênio do Nascimento, 610 - Bairro Dom Bosco - CEP: 36038-330 - Juiz de Fora, MG. \\ ${ }^{4}$ Depto. de Biologia Geral - UFV - CEP: 36571-000 - Viçosa, MG. \\ *Autor correspondente<aldos@censanet.com.br>
}

\begin{abstract}
RESUMO: O coeficiente de repetibilidade é amplamente usado pelos geneticistas como medida do limite superior da herdabilidade e da eficiência da predição do valor genotípico a partir de sucessivas medições no indivíduo. Pelo seu conhecimento pode-se avaliar se o número de avaliações realizadas é suficiente para se inferir sobre a superioridade genotípica com determinado grau de certeza. Estimou-se o coeficiente de repetibilidade das características forrageiras proteína bruta do colmo e da folha, em 77 acessos do Banco Ativo de Germoplasma de Capim-Elefante da Embrapa. O delineamento experimental foi em blocos ao acaso com duas repetições. Os cortes foram realizados aos 30, 45, 60 e 75 dias de idade, em 15 perfilhos, tomados ao acaso dentro de cada parcela. Foi realizada análise de variância dos dados obtidos para cada característica, como também estimados os parâmetros genéticos e ambientais. Os coeficientes de repetibilidade foram estimados através dos métodos: análise de variância, componentes principais - matriz de correlação, componentes principais - matriz de covariância e análise estrutural - matriz de correlação. Constatou-se variabilidade genética entre os genótipos para as características avaliadas, possibilitando a identificação de materiais genéticos superiores que podem ser utilizados em programas de melhoramento. Os coeficientes de repetibilidade estimados não apresentaram diferenças discrepantes com relação às características estudadas. Os quatro cortes foram suficientes para obter um coeficiente de determinação de 0,80 , para todos os métodos. $O$ acréscimo de três cortes, totalizando sete, torna possível obter predições com uma confiabilidade em torno de 0,90 para as características estudadas, utilizando-se qualquer dos métodos.
\end{abstract}

Palavras-chave: Pennisetum purpureum, variabilidade genética, forragem, cortes, proteína bruta

\section{REPEATABILITY OF ELEPHANTGRASS FORAGE TRAITS}

\begin{abstract}
The repeatability coefficient is widely used by geneticists as a measure of the upper limit of the heritability and as an efficient tool for predicting genotype value from successive measurements on individuals. It also allows to estimate whether the number of evaluations is sufficient to determine genotype superiority within a certain degree of reliability. The purpose of this research was to evaluate the coefficient of repeatability of crude protein concentration on stems and leaves, in 77 accesses of the Embrapa's Elephantgrass Germplasm Active Bank. The experimental design consisted of was randomized blocks, with two replicates. Forage was cut on 30,45, 60 and 75 days of croping, using 15 sprouts of each experimental unit. ANOVA was performed for each trait data set, and genetic and environmental parameters were determined. The repeatability coefficients were estimated by the methods: Analysis of variance, principal components - correlation matrix, principal components - co-variance matrix and structural analysis - correlation matrix. Genetic variability was found among the genotypes for the appraised traits, which allowed the identification of genetically superior material that can be used in breeding programs. The coefficients of estimated repeatability were not different for the traits studied. Four cuts were enough for a coefficient of determination of 0.80 , for all the methods. The use of seven cuts may enable predictions with 0.90 reliability for the studied traits, using any method.
\end{abstract}

Key words: Pennisetum purpureum, genetic variability, forage, cuts, crude protein

\section{INTRODUÇÃO}

O capim-elefante (Pennisetum purpureum Schum.) é uma gramínea de alto potencial de produção de matéria seca, que se adapta muito bem às condições de clima e solo de praticamente todo o Brasil (Deresz \& Mozzer, 1997; Deresz, 1999), sendo atualmente considerado uma das forrageiras mais importantes e difundidas no país. É uma planta perene, com crescimento cespitoso, porte elevado, colmos eretos, cilíndricos e cheios, folhas largas e compridas, inflorescência primária terminal do tipo panícula e abundante lançamento de perfilhos aéreos e basais (Nascimento Jr., 1975; Bogdan, 1977). Apresenta grande eficiência fotossintética, desenvolvendo-se bem ao nível do mar e em altitudes de até $2.200 \mathrm{~m}$ (Faria, 1999). Sua rápida disseminação está relacionada com o elevado potencial de produção, podendo atingir até 300 t/ha/ano de matéria verde (Carvalho, 1985).

${ }^{1}$ Parte da Tese de Doutorado do primeiro autor apresentada à UFV - Viçosa, MG. 
O coeficiente de repetibilidade de uma característica pode ser conceituado, estatisticamente, como sendo a correlação entre as medidas consecutivas em um mesmo indivíduo (Lush, 1964; Abeywardena, 1972; Kempthorne, 1973; Cruz \& Regazzi, 1997). Segundo Falconer (1981), quando várias medidas de uma mesma característica puderem ser feitas em um indivíduo, a variância fenotípica poderá ser parcelada, servindo para quantificar o ganho em precisão, pela repetição das medidas, e também para esclarecer a natureza da variação causada pelo ambiente.

Torna-se possível, por meio das estimativas dos coeficientes de repetibilidade, determinar quantas medições devem ser feitas em cada indivíduo, para que a seleção fenotípica entre os genótipos seja realizada com eficiência e com um mínimo custo e mão-de-obra (Cornacchia et al., 1995; Cruz \& Regazzi, 1997; Pereira et al., 1998; Ferreira et al., 1999).

O coeficiente de repetibilidade tem sido estimado por meio de vários métodos, como o da análise de variância, tradicionalmente utilizado na estimação da repetibilidade, dos componentes principais (Abeywardena, 1972; Rutledge, 1974), e o da análise estrutural (Mansour et al., 1981). Esses métodos foram aplicados em várias culturas, dentre elas pinus (Cornacchia et al., 1995), cacau (Dias \& Kageyama, 1998; Carvalho, 1999) e alfafa (Pereira et al., 1998; Ferreira et al., 1999), as quais foram avaliadas para uma determinada característica, mais de uma vez, no mesmo indivíduo, durante sua vida.

Este trabalho teve como objetivos: estimar o coeficiente de repetibilidade para as características proteína bruta do colmo e da folha; estimar o número mínimo de medições necessárias para predizer o valor real dos genótipos, com base em cinco coeficientes de determinação preestabelecidos $(0,80,0,85,0,90,0,95 \mathrm{e}$ 0,99 ); e calcular o coeficiente de determinação para cada característica, com base na média dos quatro cortes e na estimação dos coeficientes de repetibilidade obtidos de acordo com cada um dos quatro diferentes métodos utilizados.

\section{MATERIAL E MÉTODOS}

Neste trabalho, foi estudado o comportamento de genótipos de capim-elefante a partir de dados provenientes de um experimento conduzido na Embrapa Gado de Leite, município de Coronel Pacheco-MG, situado a $43^{\circ} 15^{\prime} 44^{\prime \prime}$ longitude sul, $21^{\circ} 35^{\prime} 04^{\prime \prime}$ latitude oeste e altitude de $426 \mathrm{~m}$.

Foram avaliados 77 acessos do Banco Ativo de Germoplasma de Capim-Elefante da Embrapa (BAGCE), em quatro cortes sucessivos. O experimento foi implantado em solo classificado como Latossolo Vermelho-Amarelo, de meia encosta, representativo da região. Entre os acessos avaliados estão cultivares melhoradas, clones e introduções de várias regiões do país e do exterior, que no presente trabalho são referidos como acessos ou genótipos.

Os tratamentos foram dispostos num esquema de parcelas subdivididas, tendo nas parcelas os 77 acessos e nas subparcelas os quatro cortes, no delineamento de blocos ao acaso, com duas repetições. Cada parcela foi constituída de uma linha de 2,00 m, e o espaçamento entre as linhas de diferentes parcelas foi de $2,50 \mathrm{~m}$. Os cortes foram realizados na área útil $(4,25$ $\mathrm{m}^{2}$ ) de cada parcela.

A correção do solo e a adubação foram planejadas com base nos resultados das análises química e granulométrica e no requerimento nutricional da espécie. O plantio foi realizado com mudas (pedaços de colmos), em sulcos com 0,20 m de profundidade. Nos locais onde ocorreram falhas na brotação (distância superior a 0,30 m entre duas brotações no mesmo sulco), foi realizado o replantio. Após a fase de estabelecimento dos acessos, cerca de 90 dias após o plantio, todos os tratamentos foram cortados a $0,30 \mathrm{~m}$ da superfície do solo, procedendo-se, assim, ao início da fase de coleta de dados.

Os acessos foram avaliados durante a fase vegetativa. A produção de matéria seca de folha e de colmo foi avaliada após cortes, realizados a $0,50 \mathrm{~m}$ de altura do solo, aos $30,45,60$ e 75 dias de idade, em 15 perfilhos, tomados ao acaso dentro de cada parcela. A separação da folha e do colmo foi feita em laboratório, e as amostras das forragens foram pesadas e levadas à estufa, com ar forçado a $65^{\circ} \mathrm{C}$, até atingir peso constante, sendo assim estimado o teor de matéria seca. As análises da porcentagem de proteína bruta na matéria seca foram realizadas segundo a metodologia da AOAC (1990). No presente trabalho, as características proteína bruta do colmo e proteína bruta da folha são referidas como PB colmo e PB folha.

Foram realizadas as análises de variância dos dados obtidos de cada característica avaliada, com a finalidade de verificar a existência de variabilidade genética entre os genótipos. O modelo estatístico utilizado foi o de parcelas subdivididas, considerando os efeitos de blocos e de genótipos como aleatórios e o efeito de cortes como fixo, segundo Steel et al. (1997): $\mathrm{Y}_{\mathrm{ijk}}=\mu+\mathrm{G}_{\mathrm{i}}+\mathrm{B}_{\mathrm{j}}+\varepsilon_{\mathrm{a}}+\mathrm{C}_{\mathrm{k}}+\varepsilon_{\mathrm{b}}+\mathrm{GC}_{\mathrm{ik}}+\varepsilon_{\mathrm{c}}$ em que $\mathrm{Y}_{\mathrm{ijk}}=$ valor observado, relativo ao i-ésimo genótipo no j-ésimo bloco, no k-ésimo corte; $\mu=$ média geral; $G_{i}=$ efeito aleatório do i-ésimo genótipo confundido com os efeitos ambientais permanentes $\left(\mathrm{i}=1, \ldots, \mathrm{g} ; \mathrm{g}=77\right.$ ); $\mathrm{B}_{\mathrm{j}}=$ efeito do j-ésimo bloco $(j=1, \ldots, r ; r=2) ; \varepsilon_{a}=$ efeito do erro a associado ao i-ésimo genótipo no j-ésimo bloco, sendo $\varepsilon_{\mathrm{a}} \sim \operatorname{NID}\left(0, \sigma_{\varepsilon_{\mathrm{a}}}^{2}\right) ; \mathrm{C}_{\mathrm{k}}=$ efeito fixo do k-ésimo corte $(\mathrm{k}=$ $1, \ldots, c ; c=4) ; \varepsilon_{b}=$ efeito do erro $b$ associado ao j-ésimo bloco, no k-ésimo corte, sendo $\varepsilon_{\mathrm{b}} \sim \operatorname{NID}\left(0, \sigma_{\varepsilon_{\mathrm{b}}}^{2}\right) ; \mathrm{GC}_{\mathrm{ik}}=$ efeito da interação do i-ésimo genótipo com o k-ésimo 
corte; e $\varepsilon_{\mathrm{c}}=$ efeito do erro $\mathrm{c}$ associado ao i-ésimo genótipo no j-ésimo bloco, no k-ésimo corte, sendo $\varepsilon_{\mathrm{c}} \sim$ $\operatorname{NID}\left(0, \sigma_{\varepsilon_{\mathrm{c}}}^{2}\right)$.

Foram estimados os seguintes parâmetros genéticos e ambientais descritos a seguir. Nestas expressões, QM refere-se aos quadrados médios dos respectivos efeitos especificados no modelo.

1. Variância genotípica

$$
\hat{\sigma}_{\mathrm{g}}^{2}=\left(\mathrm{QMG}-\mathrm{QM} \varepsilon_{\mathrm{a}}\right) / \mathrm{rc}
$$

em que o valor de $\hat{\sigma}_{\mathrm{g}}^{2}$ é uma estimativa superestimada da variância genotípica, em razão da existência de efeitos ambientais permanentes associados aos efeitos genotípicos.

2. Variância fenotípica

$$
\hat{\sigma}_{\mathrm{f}}^{2}=\mathrm{QMG} / \mathrm{rc}
$$

3. Componente quadrático do corte

$$
\hat{\Phi}_{\mathrm{c}}=\left[\left(\mathrm{QMC}+\mathrm{QM} \varepsilon_{\mathrm{c}}\right)-\left(\mathrm{QMGC}+\mathrm{QM} \varepsilon_{\mathrm{b}}\right)\right] / \mathrm{rg}
$$

4. Variância da interação genótipos $x$ cortes

$$
\hat{\sigma}_{\mathrm{gc}}^{2}=\left(\mathrm{QMGC}-\mathrm{QM \varepsilon _{ \textrm {c } }}\right) / \mathrm{r} \ell
$$

5. Valor máximo da herdabilidade

$$
\mathrm{h}^{2}=\hat{\sigma}_{\mathrm{g}}^{2} / \hat{\sigma}_{\mathrm{f}}^{2}=\left(\mathrm{QMG}-\mathrm{QM} \varepsilon_{\mathrm{a}}\right) / \mathrm{QMG}
$$

em que o valor de $h^{2}$ é uma estimativa superestimada da herdabilidade, por considerar as associações genéticas confundidas com as variações ambientais permanentes.

6. Coeficiente de variação genético

$$
\hat{\mathrm{CV}}_{\mathrm{g}}=\left(100 \sqrt{\hat{\sigma}_{\mathrm{g}}^{2}}\right) / \hat{\mu}
$$

7. Coeficiente de variação associado ao erro a

$$
\hat{\mathrm{CV}}_{\varepsilon_{\mathrm{a}}}=\left(100 \sqrt{\mathrm{QM \varepsilon _{ \textrm {a } }}}\right) / \hat{\mu}
$$

As estimativas de repetibilidade variam de acordo com a natureza da característica, com as propriedades genéticas da população e com as condições sob as quais os indivíduos são mantidos (Falconer, 1981; Cruz \& Regazzi, 1997). As análises foram realizadas a partir da média das repetições. Para avaliar a consistência das estimativas e tirar conclusões mais precisas sobre as características avaliadas, foram utilizados, para estimação dos coeficientes de repetibilidade, os seguintes métodos: análise de variância, componentes principais por meio da matriz de correlação intraclasse e da matriz de variância e covariância fenotípica, e análise estrutural por meio da matriz de correlação, citados por Cruz \& Regazzi (1997), cujos procedimentos estão apresentados a seguir, de forma resumida.

\section{Método da análise de variância}

O coeficiente de repetibilidade foi estimado por meio da correlação intraclasse obtida da análise de variância, considerando o modelo estatístico reduzido, com base em médias de cortes e genótipos:

$$
\mathrm{Y}_{\mathrm{ik}}=\mu+\mathrm{g}_{\mathrm{i}}+\mathrm{c}_{\mathrm{k}}+\varepsilon_{\mathrm{ik}}
$$

em que $\mathrm{Y}_{\mathrm{ik}}=$ valor médio observado, relativo ao i-ésimo genótipo, no k-ésimo corte; $\mu$ = média geral; $g_{i}=$ efeito aleatório do i-ésimo genótipo sob influência do ambiente permanente $(i=1, \ldots, p ; p=77) ; c_{k}=$ efeito fixo do ambiente temporário no k-ésimo corte $(\mathrm{k}=1, \ldots, \eta ; \eta=$ 4); e $\varepsilon_{\mathrm{ik}}=$ erro experimental estabelecido pelos efeitos temporários do ambiente no k-ésimo corte, do i-ésimo genótipo. Neste efeito, são incluídas, em uma única fonte, denotada por resíduo, todas as demais fontes de variação não consideradas no modelo.

$\mathrm{Na}$ Tabela 1, encontra-se o esquema da análise de variância desse modelo estatístico.

$\mathrm{O}$ coeficiente de repetibilidade $\mathrm{r}$ é obtido por:

$$
\mathrm{r}=\frac{\hat{\operatorname{COV}}\left(\mathrm{Y}_{\mathrm{ik}}, \mathrm{Y}_{\mathrm{ik}}\right)}{\sqrt{\hat{\mathrm{V}}\left(\mathrm{Y}_{\mathrm{ik}}\right) \hat{\mathrm{V}}\left(\mathrm{Y}_{\mathrm{ik}}\right)}}=\frac{\hat{\sigma}_{\mathrm{g}}^{2}}{\hat{\sigma}_{\mathrm{e}}^{2}+\hat{\sigma}_{\mathrm{g}}^{2}}
$$

em que $\hat{\sigma}_{\mathrm{g}}^{2}=(\mathrm{QMG}-\mathrm{QME}) / \mathrm{c} \hat{\sigma}_{\mathrm{e}}^{2}=\mathrm{QME}$

\section{Método dos componentes principais}

Este método, utilizado por Abeywardena (1972), permite estimar o coeficiente de repetibilidade de duas maneiras: a primeira por meio da matriz de correlação e a outra por meio da matriz de variâncias e covariâncias fenotípicas. É mais adequado para situações em que os genótipos avaliados apresentam comportamento cíclico em relação às características estudadas.

\section{Método dos componentes principais - matriz de correlação}

Este método consiste na obtenção de uma matriz de correlação entre os genótipos em cada par de cortes. Nesta matriz, são determinados os autovalores $(\lambda)$ e os autovetores $(\alpha)$ normalizados de R. $O$ autovetor

Tabela 1 - Esquema da análise de variância e das esperanças dos quadrados médios de um modelo em blocos ao acaso, com efeitos de genótipo aleatório e corte fixo.

\begin{tabular}{lcccc}
\hline FV & GL & QM & $\mathrm{E}(\mathrm{QM})^{1 /}$ & $\mathrm{F}$ \\
\hline Ge nótipo & $\mathrm{g}-1$ & $\mathrm{QMG}$ & $\sigma_{\mathrm{e}}^{2}+\mathrm{c} \sigma_{\mathrm{g}}^{2}$ & $\mathrm{QMG} / \mathrm{QME}$ \\
Corte & $\mathrm{c}-1$ & $\mathrm{QMC}$ & $\sigma_{\mathrm{e}}^{2}+\mathrm{p} \Phi_{\mathrm{c}}$ & $\mathrm{QMC} / \mathrm{QME}$ \\
Resíduo & $(\mathrm{g}-1)(\mathrm{c}-1)$ & $\mathrm{QME}$ & $\sigma_{\mathrm{e}}^{2}$ & \\
\hline
\end{tabular}

${ }^{1 /} \sigma_{\mathrm{e}}^{2}=$ componente de variância devido ao erro; $\sigma_{\mathrm{g}}^{2}=$ componente de variância devido a genótipos; e $\Phi_{\mathrm{c}}=$ componente quadrático associado aos efeitos de cortes, sendo $\Phi_{\mathrm{c}}=\sum_{\mathrm{k}=1}^{\mathrm{c}} \mathrm{c}_{\mathrm{i}}^{2} /(\mathrm{c}-1)$. 
cujos elementos apresentam mesmo sinal e magnitudes próximas é aquele que expressa a tendência de os genótipos manterem suas posições relativas nos vários intervalos de cortes. O estimador do coeficiente de repetibilidade é a proporção do autovalor associado a esse autovetor, que é expresso por:

$$
r=\frac{\lambda_{\mathrm{k}}}{\sum_{\mathrm{j}} \lambda_{\mathrm{j}}}
$$

sendo $\mathrm{j}=1,2, \ldots, \eta$ em que $\eta=$ número de cortes avaliados; e $\lambda_{k}$ autovalor associado ao autovetor, cujos elementos têm mesmo sinal e magnitude semelhante.

Rutledge (1974), relatou que $\lambda_{k}$ é influenciado pelo número de medições dos indivíduos; assim sendo, o estimador $r$ torna-se mais adequado à estimação do coeficiente de repetibilidade, que é obtido por:

$$
\mathrm{r}=\frac{\hat{\lambda}_{1}-1}{\eta-1}
$$

em que $\lambda_{1}=1+(\lambda-1) \rho$ em que $\hat{\lambda}_{1}$ é o autovalor de $R$ associado ao autovetor cujos elementos têm mesmo sinal e magnitude semelhantes; $\eta=$ número de cortes; $\mathrm{e}$ $\rho=$ número de genótipos.

\section{Método dos componentes principais - matriz de covariância}

Uma alternativa para estimar o coeficiente de repetibilidade com o uso do método de componentes principais é por meio da aplicação da matriz de variâncias e covariâncias fenotípicas $(\Gamma)$.

Neste caso, o estimador do coeficiente de repetibilidade é obtido por:

$$
\mathrm{r}=\frac{\hat{\lambda}_{1}-\hat{\sigma}_{\mathrm{Y}}^{2}}{\hat{\sigma}_{\mathrm{Y}}^{2}(\eta-1)}
$$

em que $\lambda_{1}$ é o autovalor $\hat{\Gamma}$ associado ao autovetor cujos elementos têm mesmo sinal e magnitude semelhantes; $\hat{\sigma}_{\mathrm{y}}^{2}=\hat{\sigma}_{\mathrm{g}}^{2}+\hat{\sigma}_{\mathrm{e}}^{2}$ e $\eta=$ número de cortes.

\section{Método da análise estrutural - matriz de correlação}

Mansour et al. (1981) propuseram o método da análise estrutural para estimar o coeficiente de repetibilidade. Neste método, considera-se R a matriz paramétrica de correlações entre os genótipos em cada par de avaliação e $\hat{R}$ o seu estimador.

Um estimador do coeficiente de repetibilidade com base na análise estrutural é expresso por:

$$
r=\frac{\alpha^{\prime} \hat{R} \alpha-1}{\eta-1}
$$

em que $\alpha^{\prime}$ é o autovetor com elementos paramétricos, associados ao maior autovalor da matriz de correlação uniforme $\mathrm{R}$, que é dado por:

$$
\alpha^{\prime}=\left[\frac{1}{\sqrt{\eta}} \cdots \frac{1}{\sqrt{\eta}}\right]
$$

\section{Número de medições}

Para cada característica, o número mínimo de medições necessárias para predizer o valor real dos genótipos, com base em um coeficiente de determinação $\left(R^{2}\right)$ preestabelecido $(0,80,0,85,0,90,0,95$ e 0,99$)$, foi calculado por Cruz \& Regazzi (1997), por meio da seguinte expressão:

$$
\eta_{\mathrm{m}}=\frac{\mathrm{R}^{2}(1-\mathrm{r})}{\left(1-\mathrm{R}^{2}\right) \mathrm{r}}
$$

em que $\eta_{m}=$ número de medições para predição do valor real; $R^{2}=$ coeficiente de determinação; e $r=$ coeficiente de repetibilidade obtido de acordo com um dos diferentes métodos utilizados.

\section{Coeficiente de determinação}

Para cada característica, com base na média dos $\eta$ cortes $(\eta=4)$ e na estimação dos coeficientes de repetibilidade obtidos de acordo com um dos diferentes métodos utilizados, foi calculado o coeficiente de determinação $\left(R^{2}\right)$ por meio da seguinte expressão:

$$
\mathrm{R}^{2}=\frac{\eta \mathrm{r}}{1+\mathrm{r}(\eta-1)}
$$

Todas as análises estatísticas foram realizadas com o uso do programa computacional GENES (Cruz, 1997).

\section{RESULTADOS E DISCUSSÃO}

Os resultados das análises de variância dos dados das características PB colmo e PB folha, avaliadas em 77 genótipos de capim-elefante, encontram-se na Tabela 2. Os efeitos de genótipos e de cortes foram significativos $(P<0,01)$ para as características estudadas. Tal fato indica a existência da variabilidade genética, o que possibilita a identificação de genótipos promissores, os quais podem ser utilizados em programas de melhoramento. Já a interação genótipos $x$ cortes não apresentou significância $(P>0,05)$, mostrando que o comportamento dos genótipos foi semelhante em relação aos diferentes cortes.

As estimativas do coeficiente de variação genética $\left(\mathrm{CV}_{\mathrm{q}}\right)$ são muito importantes num programa de melhoramento, pois indicam a amplitude de variação genética de uma característica (Tabela 2). As estimativas para as características PB folha e PB colmo foram 7,56 e $13,68 \%$, respectivamente. O coeficiente de variação experimental $\left(\mathrm{CV}_{\varepsilon_{\mathrm{a}}}\right)$ no qual foram alocados os genótipos e que serve de parâmetro para verificar a precisão experimental da variação genética, foi de $13,71 \%$ para PB folha e de $18,09 \%$ para PB colmo. Esses resultados foram contraditórios, pois as melhores precisões experimentais obtidas não permitiram as maiores expressões da variabilidade genotípica (Tabela 2). 
Tabela 2 - Resumo da análise de variância e estimação dos parâmetros genéticos e ambientais das características PB colmo e PB folha, obtidas de dados de 77 genótipos de capim-elefante ${ }^{1 /}$.

\begin{tabular}{lrcc}
\hline \multirow{2}{*}{ Fonte de Variação } & \multicolumn{3}{c}{ QM } \\
\cline { 2 - 4 } & $\mathrm{GL}$ & $\mathrm{PB}$ colmo & PB folha \\
\hline Bloco & 1 & 669,2037 & 216,6265 \\
Genótipo & 76 & $11,8630^{\star *}$ & $14,4393^{\star *}$ \\
Erro a & 76 & 2,1280 & 4,2064 \\
Corte & 3 & $4957,5155^{\star *}$ & $3066,6624^{\star *}$ \\
Erro b & 3 & 163,5114 & 96,4709 \\
Genótipo x Corte & 228 & $1,5445^{\text {ns }}$ & $2,3402^{\text {ns }}$ \\
Erro c & 228 & 1,6522 & 1,9894 \\
\hline Média & & 8,0659 & 14,9565 \\
Componente de variância genotípica ${ }^{2 /}\left(\sigma_{\mathrm{g}}^{2}\right)$ & 1,2169 & 1,2791 \\
Componente de variabilidade do corte $\left(\Phi_{\mathrm{g}}\right)$ & & 31,1306 & 19,2847 \\
Valor máximo da herdabilidade $-\mathrm{h}^{2}(\%)$ & & 82,06 & 70,87 \\
Coeficiente de variação genético $\mathrm{CV}_{\mathrm{g}}(\%)$ & 13,68 & 7,56 \\
Coeficiente de variação experimental $\mathrm{CV}_{\varepsilon_{\mathrm{a}}}(\%)$ & & 18,09 & 13,71 \\
\hline
\end{tabular}

${ }^{* *}$ Significativo a $1 \%$ de probabilidade pelo teste $\mathrm{F}$; e ns não-significativo a $5 \%$ teste $\mathrm{F}$.

${ }^{1 / P B}=$ proteína bruta; ${ }^{2 /}$ Componente de variância genotípica confundido com os efeitos permanentes dos ambientes.

O valor máximo da herdabilidade expressa a proporção da variância fenotípica que é atribuída às diferenças genéticas confundidas com os efeitos ambientais permanentes que atuam nos genótipos (Falconer 1981). Esse valor mede o grau de determinação genética da característica e é usualmente mais fácil de ser determinado, pois não exige cruzamentos controlados e estudos com progênies. A variância causada pelo ambiente permanente é uma fonte de erro que reduz a precisão nos estudos genéticos, devendo-se ressaltar que o melhorista sempre procura reduzi-la o máximo possível por meio de um manejo cuidadoso, permitindo, dessa forma, que o valor do coeficiente de repetibilidade torne-se o mais próximo da estimativa da herdabilidade. O conhecimento do valor máximo da herdabilidade, no caso de culturas perenes como o capim-elefante, é fundamental, pois é grande o intervalo de tempo que vai do início da experimentação, passando pelas avaliações realizadas por meio de medições sucessivas no mesmo indivíduo, até a seleção de materiais genéticos promissores. As estimativas do valor máximo da herdabilidade foram consideradas de magnitude satisfatórias para as características PB folha $(70,87)$ e PB colmo (82,06), o que torna viável a seleção de materiais genéticos superiores.

\section{Método da análise de variância}

Os resultados da análise de variância e as estimativas dos parâmetros para cálculo dos coeficientes de repetibilidade das características avaliadas pelo método da análise de variância encontram-se na Tabela 3.

Os coeficientes de repetibilidade estimados por esse método foram superiores a 0,5638 , considerados razoáveis, uma vez que a predição do valor real, que é expressa pelo coeficiente de determinação, foi de 0,8379 (Tabela 4).
Tabela 3 - Análise de variância (modelo reduzido) e estimativas de parâmetros para cálculo dos coeficientes de repetibilidade dascaracterísticas PB colmo e PB folha, de 77 genótipos de capimelefante $^{1 /}$

\begin{tabular}{lrcc}
\hline \multirow{2}{*}{ Fonte de Variação } & \multicolumn{3}{c}{ QM } \\
\cline { 2 - 4 } & $\mathrm{GL}$ & $\mathrm{PB}$ colmo & \multicolumn{1}{c}{ PB folha } \\
\hline Corte (C) & 3 & $2478,7578^{\star \star}$ & $1533,3312^{\star *}$ \\
Genótipo (G) & 76 & $5,9315^{\star \star}$ & $7,2197^{\star *}$ \\
Resíduo (GxC) & 228 & 0,7723 & 1,1701 \\
\hline Média & & 8,0659 & 14,9565 \\
$\sigma_{\mathrm{e}}^{2}$ & & 0,7723 & 1,1701 \\
$\sigma_{\mathrm{g}}^{2}$ & & 1,2898 & 1,5124 \\
\hline
\end{tabular}

"Significativo a $1 \%$ pelo teste $F$, feito com base nas fontes de variações especificadas na Tabela 2.

${ }^{1 /} \mathrm{PB}=$ proteína bruta.

O número mínimo de medições necessárias para predizer o valor real dos genótipos, com base em um coeficiente de determinação preestabelecido, para cada característica, encontra-se na Tabela 5.

O número de medições realizadas para as características estudadas foi suficiente para atingir o coeficiente de determinação de 0,80.

\section{Método dos componentes principais - matriz de correlação}

As estimativas dos coeficientes de repetibilidade (r) e dos coeficientes de determinação $\left(R^{2}\right)$, considerando quatro cortes, foram, respectivamente, para $\mathrm{PB}$ folha 0,5821 e 0,8478 e para PB colmo 0,6571 e 0,8845 (Tabela 4). Esses valores podem ser considerados razoáveis, e se o melhorista se basear nesses quatro cortes terá condições favoráveis para obter sucesso na identificação de genótipos superiores.

\section{Método dos componentes principais - matriz de covariância}

Os procedimentos estatísticos utilizados neste método foram os mesmos do método anterior, tendo sido, 
neste caso, empregada a matriz de covariância para estimação dos parâmetros, para cálculo das estimativas dos coeficientes de repetibilidade.

As estimativas dos coeficientes de repetibilidade $(r)$ e dos coeficientes de determinação $\left(R^{2}\right)$, considerando quatro cortes, foram, respectivamente, para PB folha 0,5690 e 0,8407 e para PB colmo 0,6443 e 0,8787 (Tabela 4 ), confirmando, de certo modo, que a matriz de covariância possui qualidade para tal estudo. De modo geral, os valores das estimativas de repetibilidade indicam que o melhorista tem possibilidade de obter sucesso na identificação de genótipos superiores, desde que leve em consideração os desempenhos nos quatro cortes.

\section{Método da análise estrutural - matriz de correlação}

Este método, proposto por Mansour et al. (1981), apresenta apenas diferenças conceituais em relação ao dos componentes principais proposto por Abeywardena (1972). Os autores consideram $\mathrm{R}$ a matriz paramétrica de correlações entre os genótipos em cada par de medição e $\hat{R}$ o seu estimador.
As estimativas dos coeficientes de repetibilidade foram obtidas pela média aritmética das correlações fenotípicas entre os genótipos, considerando cada par de medições. As estimativas dos coeficientes de repetibilidade ( $r)$ e dos coeficientes de determinação $\left(R^{2}\right)$, considerando os quatro cortes, foram, respectivamente, para PB folha 0,5739 e 0,8434 e para PB colmo 0,6416 e 0,8774 (Tabela 4). De acordo com esses resultados, o melhorista deverá basear-se nos desempenhos em quatro cortes, de maneira a ter sucesso na identificação de melhores genótipos.

Os gráficos que contêm os coeficientes de determinação, considerando quatro cortes, em relação aos quatro métodos de estimação do coeficiente de repetibilidade, para as características PB colmo e PB folha, encontram-se nas Figuras 1 e 2, respectivamente. Para as características estudadas, qualquer uma das metodologias, considerando os quatro cortes, seria suficiente para que o processo de seleção realizado pelo melhorista tenha $80 \%$ de confiabilidade e para que o comportamento de superioridade ou inferioridade

Tabela 4 - Estimativas dos coeficientes de repetibilidade $(r)$ e coeficientes de determinação $\left(R^{2}\right)$ das características PB colmo e PB folha, obtidos de dados de 77 genótipos de capim-elefante, avaliados por quatro métodos ${ }^{1 /}$.

\begin{tabular}{lcccc}
\hline \multirow{2}{*}{ Método } & \multicolumn{2}{c}{ PB colmo } & \multicolumn{2}{c}{ PB folha } \\
\cline { 2 - 5 } & $\mathrm{r}$ & $\mathrm{R}^{2}$ & $\mathrm{r}$ & $\mathrm{R}^{2}$ \\
Análise de variância & 0,6255 & 0,8698 & 0,5638 & 0,8379 \\
Componente principal - correlação & 0,6571 & 0,8845 & 0,5821 & 0,8478 \\
Componente principal - covariância & 0,6443 & 0,8787 & 0,5690 & 0,8407 \\
Análise estrutural - correlação & 0,6416 & 0,8774 & 0,5739 & 0,8434 \\
\hline
\end{tabular}

${ }^{1 / P B}=$ proteína bruta.

Tabela 5 - Número de medições das características PB colmo e PB folha, obtidos de dados de 77 genótipos de capimelefante, associados a diferentes graus de determinação do valor genotípico $\left(R^{2}\right)$, em quatro métodos de estimação de coeficiente de repetibilidade ${ }^{1 /}$.

\begin{tabular}{|c|c|c|c|}
\hline \multirow{2}{*}{$\mathrm{R}^{2}$} & \multirow{2}{*}{ Método } & \multicolumn{2}{|c|}{ Característica } \\
\hline & & PB colmo & PB folha \\
\hline 0,80 & Análise de variância & 3 & 4 \\
\hline & Componentes Principais (correlação) & 3 & 3 \\
\hline & Componentes Principais (covariância) & 3 & 4 \\
\hline & Análise Estrutural (correlação) & 3 & 3 \\
\hline 0,85 & Análise de Variância & 4 & 5 \\
\hline & Componentes Principais (correlação) & 3 & 5 \\
\hline & Componentes Principais (covariância) & 4 & 5 \\
\hline & Análise Estrutural (correlação) & 4 & 5 \\
\hline 0,90 & Análise de Variância & 6 & 7 \\
\hline & Componentes Principais (correlação) & 5 & 7 \\
\hline & Componentes Principais (covariância) & 5 & 7 \\
\hline & Análise Estrutural (correlação) & 6 & 7 \\
\hline 0,95 & Análise de Variância & 12 & 15 \\
\hline & Componentes Principais (correlação) & 10 & 14 \\
\hline & Componentes Principais (covariância) & 11 & 15 \\
\hline & Análise Estrutural (correlação) & 11 & 15 \\
\hline 0,99 & Análise de Variância & 60 & 77 \\
\hline & Componentes Principais (correla ção) & 52 & 72 \\
\hline & Componentes Principais (covariância) & 55 & 75 \\
\hline & Análise Estrutural (correlação) & 56 & 74 \\
\hline
\end{tabular}

1/ $\mathrm{PB}=$ proteína bruta. 
dos genótipos seja mantido. Pode-se observar que os valores dos coeficientes de determinação $\left(R^{2}\right)$ das características são muito próximos (Tabela 4), causando um confundimento entre cada linha plotada de cada método (Figuras 1 e 2).

$\mathrm{Na}$ Tabela 5, são apresentadas as estimativas do número de medições necessárias, com base em cinco coeficientes de determinação preestabelecidos, para predizer o valor real dos genótipos em cada característica avaliada, pelos quatro procedimentos estatísticos. Para a característica PB colmo, considerando os quatro cortes realizados, o melhorista pode predizer o valor dos genótipos com $85 \%$ de confiabilidade. Já para PB folha, seria necessário o acréscimo de um corte para se obter a mesma precisão de seleção.

$\mathrm{Na}$ hipótese de haver disponibilidade de recursos e de mão-de-obra para realizar três cortes adicionais, perfazendo um total de sete, poderiam ser selecionados genótipos promissores com o uso de todos os métodos, com uma confiabilidade em torno de $90 \%$ para as características PB colmo e PB folha. Em relação à predição do valor real dos genótipos, considerando-se as características estudadas, o aumento da precisão para em torno de $95 \%$, implica a necessidade de realizar um grande número de cortes adicionais, tornando-se inviável, em conseqüência do alto custo a ser dispendido (Tabela 5).

As estimativas dos coeficientes de repetibilidade (r) e dos coeficientes de determinação $\left(R^{2}\right)$, obtidas pelas quatro metodologias estatísticas, considerando-se quatro cortes, variaram de $r=0,5638$ e $R^{2}=0,8379$ para a característica $P B$ folha (análise de variância) a $r=0,6571$ e $R^{2}=0,8845$ (componentes principais - correlação) para a característica PB colmo. Os métodos componentes principais que utilizam matriz de correlação e análise de variância foram os que proporcionaram, respectivamente, as maiores e menores estimativas de coeficientes de repetibilidade e coeficiente de determinação para as características avaliadas (Tabela 4).

De modo geral, as estimativas de repetibilidade obtidas pelas diferentes metodologias apresentaram boa concordância, mostrando consistência e confiabilidade dos resultados.

\section{CONCLUSÕES}

Os coeficientes de repetibilidade estimados por todos os métodos não apresentaram diferenças discrepantes com relação às características avaliadas.

Os quatro cortes foram suficientes para obter um coeficiente de determinação de 0,80 , pelos quatro métodos utilizados.

Com a adição de três cortes, perfazendo um total de sete, podem-se obter predições com confiabilidade em torno de 0,90 para as características avaliadas, utilizando qualquer um dos métodos.

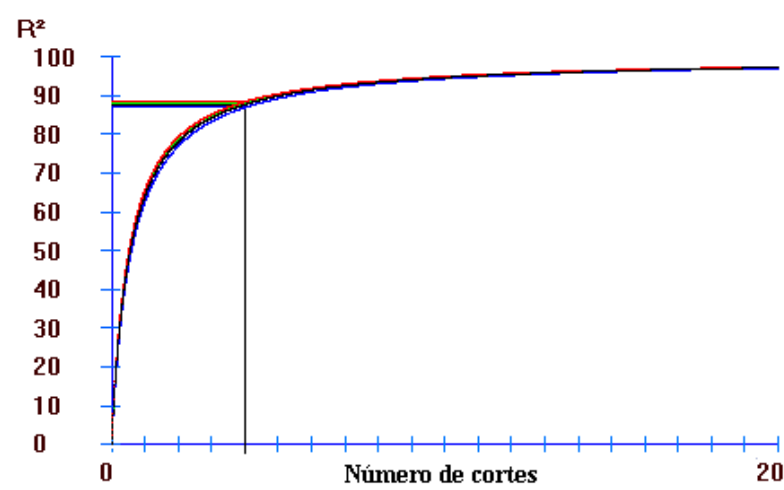

Legenda:

-.--- Método Análise de Variância; —— Método Componentes Principais - Covariância; ....... Método Componentes Principais Correlação; -..... Método Análise Estrutural - Correlação

Equação de predição de $\mathrm{R}^{2}=\frac{\eta \mathrm{r}}{1+\mathrm{r}(\eta+1)}$

Figura 1 - Gráfico do coeficiente de determinação $\left(R^{2}\right)$, em porcentagem, considerando quatro cortes, em relação aos quatro métodos de estimação do coeficiente de repetibilidade para a característica proteína bruta (PB) do colmo.

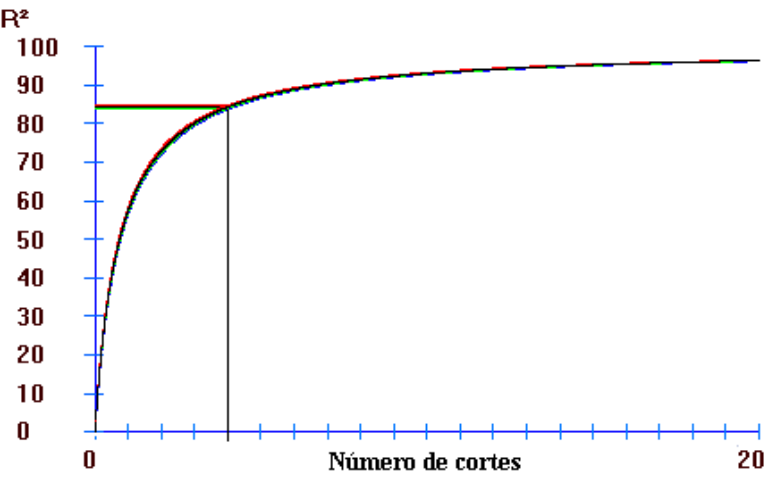

Legenda:

-.-.- Método Análise de Variância; —— Método Componentes

Principais - Covariância; ...... Método Componentes Principais -

Correlação; -..... Método Análise Estrutural - Correlação

Equação de predição de $\mathrm{R}^{2}=\frac{\eta \mathrm{r}}{1+\mathrm{r}(\eta+1)}$

Figura 2 - Gráfico do coeficiente de determinação $\left(R^{2}\right)$, em porcentagem, considerando quatro cortes, em relação aos quatro métodos de estimação do coeficiente de repetibilidade para a característica proteína bruta (PB) do colmo.

\section{REFERÊNCIAS BIBLIOGRÁFICAS}

ABEYWARDENA, V. An application of principal component analysis in genetics. Journal of Genetics, v.61, p.27-51, 1972.

ASSOCIATION OF OFFICIAL ANALYTICAL CHEMISTS. Official methods of analysis of the Association of Official Analytical Chemists. Arlington: AOAC, 1990. 1298p.

BOGDAN, A.V. Tropical pasture and fodder crops. New York: Logman, 1977. 475p.

CARVALHO, C.G.P.de. Repetibilidade e seleção de híbridos de cacaueiro. Viçosa, 1999. 177p. Tese (Doutorado) - Universidade Federal de Viçosa.

CARVALHO, L.A. Pennisetum purpureum Schumacher: revisão. Coronel Pacheco: EMBRAPA, CNPGL, 1985. 86p. (Boletim Técnico, 10)

CORNACCHIA, G.; CRUZ, C.D.; PIRES, I.E. Estimativa do coeficiente de repetibilidade para características fenotípicas de procedências de Pinus tecunumanii (Schw.) Eguiluz \& Perry e Pinus caribaea var. hondurensis Barret \& Golfari. Revista Árvore, v.19, p.333-345, 1995. 
CRUZ, C.D. Programa GENES: aplicativo computacional em genética e estatística. Viçosa: UFV, 1997. 442p

CRUZ, C.D.; REGAZZI, A.J. Modelos biométricos aplicados ao melhoramento genético. 2.ed. Viçosa: UFV, 1997. 390p.

DERESZ, F. Capim-elefante manejado em sistema rotativo para produção de leite e carne. In: PASSOS, L.P.; MARTINS, C.E.; BRESSAN, M.; PEREIRA A.V. (Ed.) Biologia e manejo do capim-elefante. Juiz de Fora: Embrapa Gado de Leite, 1999. p.131-160.

DERESZ, F.; MOZZER, O.L. Produção de leite em pastagem de capimelefante. In: CARVALHO, M.M.; ALVIM, M.J.; XAVIER, D.F.; CARVALHO, L.A. (Ed.) Capim-elefante: produção e utilização. 2.ed.rev. Brasília: EMBRAPA, SPI; Juiz de Fora: EMBRAPA, CNPGL, 1997. p.189-219.

DIAS, L.A.S.; KAGEYAMA, P.Y. Repeatability and minimum harvest period of cacao (Theobroma cacao L.) in southern Bahia. Euphytica, v.102, p.2935, 1998.

FALCONER, D.S. Introdução à genética quantitativa. Viçosa: UFV, Imprensa Universitária, 1981. 279p.

FARIA, V.P. Formas de uso do capim-elefante. In: PASSOS, L.P.; MARTINS, C.E.; BRESSAN, M.; PEREIRA, A.V. (Ed.) Biologia e manejo do capimelefante. Juiz de Fora: Embrapa Gado de Leite, 1999. p.119-130.

FERREIRA, R.P.; BOTREL, M.A.; PEREIRA, A.V.; CRUZ, C.D. Avaliação de cultivares de alfafa e estimativas de repetibilidade de caracteres forrageiros. Pesquisa Agropecuária Brasileira, v.34, p.995-1002, 1999.

KEMPTHORNE, O. An introduction to genetic statistics. 2.ed. Ames: lowa State University Press, 1973. 545p
LUSH, J.L. Melhoramento genético dos animais domésticos. Rio de Janeiro: Missão Norte-Americana de Cooperação Econômica e Técnica no Brasil - USAID, 1964. 570p.

MANSOUR, H.; NORDHEIM, E.V.; RUTLEDGE, J.J. Estimators of repeatability. Theoretical and Applied Genetics, v.60, p.151-156, 1981.

NASCIMENTO JR., D. Informações sobre algumas plantas forrageiras no Brasil. Viçosa: UFV, Imprensa Universitária, 1975. 73p.

PEREIRA, A.V.; FERREIRA, R.P.; CRUZ, C.D.; FREITAS, V.P.; OLIVEIRA P.T.A. de. Comportamento de alfafa cv. Crioula de diferentes origens e estimativas dos coeficientes de repetibilidade para caracteres forrageiros. Revista Brasileira de Zootecnia, v.27, p.686-690, 1998.

RUTLEDGE, J.J. A scaling which removes bias of Abeywardena's estimator of repeatability. Journal of Genetics, v.61, p.247-250, 1974.

STEEL, R.G.D.; TORRIE, J.H.; DICKEY, D.A. Principles and procedures of statistics: a biometrical approach. 3.ed. New York: The McGraw-Hill Companies, 1997. 666p.

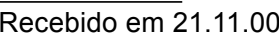

